\section{Os riscos dos acidentes de trânsito na perspectiva dos moto-boys: subsídios para a promoção da saúde}

\author{
Traffic accidents from the motorcycle couriers' \\ perspective: feedback for health promotion
}

\footnotetext{
${ }^{1}$ Escola de Enfermagem, Universidade Federal do Rio Grande do Sul, Porto Alegre, Brasil. 2 Hospital de Pronto Socorro de Porto Alegre, Porto Alegre, Brasil.

Correspondência A. M. Veronese Grupo de Estudos em Promoção da Saúde, Escola de Enfermagem, Universidade Federal do Rio Grande do Sul. Rua Comendador Castro 140, Porto Alegre, RS 91760-200, Brasil. andreamv@terra.com.br
}

\begin{abstract}
This research note is the result of a qualitative study in Porto Alegre, Rio Grande do Sul, Brazil, aimed at exploring traffic accident risk from the motorcycle couriers' point of view. The research results highlight the importance of accident prevention and health promotion for these workers. The study was based on sociological theories of risk, especially those emphasizing the social and cultural nature of its meanings. Information was gathered through focus groups and analyzed according to the Data-Based Theory. According to the research subjects, all motorcycle couriers, the traffic accident risk is inherent to their daily work duties and is produced by personal and social interests like money, speed, and urgency. Motorcycle couriers attempt to control such risks by using self-defense strategies. Considering the high incidence of traffic accidents with motorcycle couriers in Porto Alegre, these strategies have apparently not been effective. This note emphasizes that traffic accidents involving motorcycle couriers are work-related accidents, and that health promotion measures to prevent them should target not only the couriers themselves but also their employers and customers.
\end{abstract}

Traffic Accidents; Occupational Accidents; Motorcycles; Health Promotion
Andréa Márian Veronese 1,2

Dora Lúcia Leidens Corrêa de Oliveira ${ }^{1}$

\section{Introdução}

A pesquisa originou-se na prática de enfermeira no Hospital de Pronto Socorro de Porto Alegre, Porto Alegre, Rio Grande do Sul, Brasil 1. O que motivou o projeto da pesquisa foi o cotidiano dos moto-boys, comentado em conversas informais com os acidentados. Essas conversas apontavam para o fato de que o risco do acidente de trânsito é uma das especificidades do seu trabalho.

Baseada numa perspectiva sociológica do risco, a qual pressupõe que os significados de risco são definíveis pelo sujeito que vive a situação arriscada $2,3,4$, a pesquisa investigou o modo pelo qual os moto-boys vêem os riscos do acidente de trânsito no cotidiano de seu trabalho, visando a produzir subsídios para a promoção da saúde desses trabalhadores.

\section{Metodologia}

A abordagem da pesquisa foi qualitativa e as seguintes questões a nortearam: (a) De que modo os moto-boys vêem o risco pessoal de acidente de trânsito no seu cotidiano de trabalho?; para eles (b) Quais os riscos da profissão?; (c) Que elementos do seu cotidiano constituem o risco de acidente de trânsito?; e (d) Qual a atitude dos moto-boys frente ao risco do acidente de trânsito?

A pesquisa foi aprovada pelo Comitê de Ética em Pesquisa do Hospital de Pronto Socorro de 
Porto Alegre. A coleta de dados foi realizada entre junho e agosto de 2004 por meio de grupos focais ${ }^{5}$. Foram convidados 11 moto-boys, divididos em dois grupos. As falas são identificadas, nesta nota, com "S" e um número referindo-se a cada sujeito, e a letra "G" e um número referindo-se ao grupo de que o sujeito participou.

A análise das informações seguiu os passos da Teoria Fundamentada nos Dados (Grounded Theory) ${ }^{6}$. Os resultados são apresentados em duas seções: Percebendo os Riscos do Acidente de Trânsito no Cotidiano do Trabalho e Tentando o Controle dos Riscos do Acidente de Trânsito.

\section{Resultados}

Percebendo os riscos do acidente de trânsito no cotidiano do trabalho

O aumento do número de moto-boys circulando no trânsito sugere que eles desempenham tarefas que satisfazem as necessidades sociais contemporâneas, como afirma um dos sujeitos da pesquisa: “... o mercado exige, o mercado pede" (S2G2). Apesar da demanda, o trabalho é informal: "Até hoje, as empresas de telentrega não são regulamentadas” (S6G2).

As falas dos moto-boys sugerem que ingressar na profissão representa uma oportunidade de emprego: "Por que vocês acham que a profissão cresceu tanto?" (Pesquisadora); “Desemprego e facilidade que tu tem de arranjar emprego, basta tu teres uma moto. Tu teres uma moto é a mesma coisa que uma faculdade, te abre muitas portas" (S2G2).

Para os moto-boys, a sociedade os vê de forma dicotômica. Por um lado, a presença dos motoboys no trânsito das grandes cidades já está incorporada como necessária. Por outro, há críticas às condutas dos moto-boys, as quais são solicitadas pela própria.

"A sociedade criou o moto-boy, criou todo esse comodismo, e a própria sociedade é que discrimina o moto-boy. Mas, aquela mesma pessoa que te xinga na rua, que, quando tu passas, toca no retrovisor dela, ela quer receber o remédio, o documento. Aí, ela te chama pra fazer aquele serviço com pressa. Então, no trânsito, ela te discrimina; mas, para ser bem atendido, aí, ela te chama em casa" (S1G2).

Ao descrever as especificidades do seu trabalho, os moto-boys destacam a urgência e a competição. A urgência solicitada nas entregas exige altas velocidades. Essa é reconhecidamente causa de acidentes e condenada no Código de Trânsito Brasileiro 7. Mas, é tão importante no trabalho de moto-boy a ponto de garantir o seu emprego.
"Tem um amigo nosso que trabalha conosco. O cara não passa de 80" (S5G2). "Ele é calmo" (S3G2). “Mas ele arruma serviço?” (S1G2).

Quanto à competição, segundo os moto-boys, é incentivada pelos patrões e clientes.

"Há competição, principalmente quando a pessoa recebe comissionado. Então, as empresas promovem competição, e acabam fazendo até sacanagem, distribuindo entregas mais pra um do que pra outro" (S6G2).

"Sabes o que colabora pra aumentar o risco do moto-boy? Pagar duas 'bandas' ["bandas" são entregas]: quinze para às seis liguei pro Fulano: quanto é que é a tua banda? Cinco. Te dou dez pra tu estares lá às seis" (S2G1).

Há fatores humanos, ambientais e mecânicos implicados no risco do acidente de trânsito. O cansaço e a sobrecarga de tarefas são provocadores da falha humana. "Conheço uma pessoa que dormiu na moto, na madrugada, trabalhando de dia e de noite. Foi se acordar no hospital" (S5G1).

Ser um motociclista inexperiente contribui para o risco do acidente de trânsito: “[o inexperiente] não tem noção de espaço, não tem noção pra frear, não tem noção de nada" (S1G2).

O excesso de experiência, por outro lado, pode levar o moto-boy a aprender modos arriscados de dirigir: "Vai passando o tempo, vai vendo exemplos do que não deve fazer: passando sinal vermelho, pegando corredor de ônibus" (S6G2).

Entre os fatores ambientais, destaca-se a chuva. "Eu caí sozinho por causa da chuva, caí em cima de um torrão de barro, fazer o quê? Eu freei, a moto virou, eu fui pro chão" (S2G2).

Outro fator relacionado ao ambiente que contribui para a ocorrência dos acidentes de trânsito tem a ver com problemas nas vias.

"Na [avenida] Carlos Gomes, eles estavam arrumandoaquele paredão, colocaram uns canudos, só que mal sinalizados, quando o cara entrou na curva, deu de cara com aqueles canudos" (S5G2). "Ali na [avenida] Farrapos, ele entrou com a roda justamente no buraco" (S5G2). "Um cachorro se atravessou na minha frente!" (S4G2).

Os moto-boys também destacam a importância da manutenção da motocicleta.

"A tua moto tem que estar em dia" (S5G2). "Freio bom, pneu bom, isso aí já é uma boa prevenção, né?” (S5G1).

Além desses fatores há o fato de muitos moto-boys precisarem concluir suas tarefas no final de expedientes. "É todo aquele pessoal, quinze para às seis, quer entrega seis horas lá, e aí acumula tudo no final da tarde, todo mundo quer se liberar" (S5G1).

Percebe-se que o risco de acidente é um fenômeno complexo. As causas alegadas para o 
acidente potencializam-se entre si, caracterizando essa complexidade.

Corroborando os resultados do estudo de Oliveira ${ }^{8}$, o risco do acidente de trânsito não é unifocal, ele incorpora uma rede de possíveis danos, demonstrados na Figura 1.
A Figura 1 demonstra que, ser moto-boy implica conviver com a possibilidade de vários riscos e danos interconectados. A freqüente e estreita associação do arriscado com o necessário já foi abordada por Ayres et al. ${ }^{9}$ em um outro contexto. Os autores diriam que os moto-boys

Figura 1

Tipos de riscos associados ao acidente de trânsito no trabalho do moto-boy e os danos que eles podem causar.

Porto Alegre, Rio Grande do Sul, Brasil, 2004.

\begin{tabular}{|c|c|c|}
\hline $\begin{array}{l}\text { Tipos de riscos associados ao } \\
\text { acidente de trânsito no trabalho } \\
\text { do moto-boy }\end{array}$ & \multirow{6}{*}{ 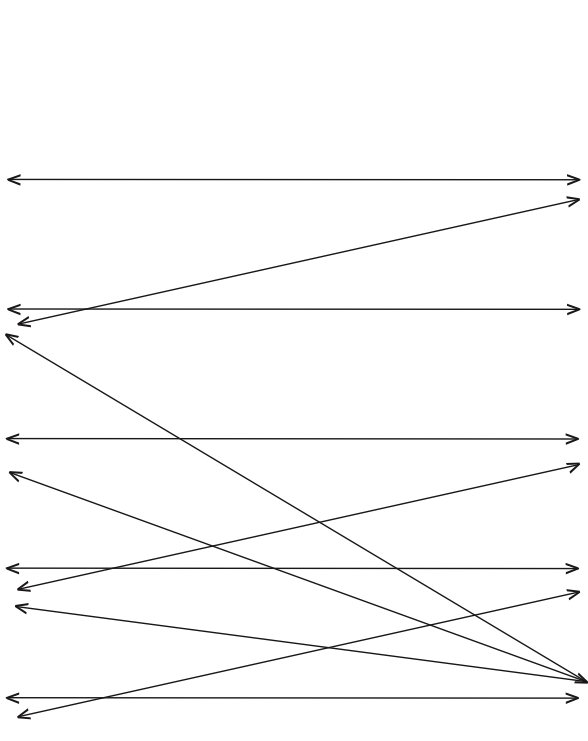 } & $\begin{array}{l}\text { Exemplos de danos que esse } \\
\text { risco pode causar }\end{array}$ \\
\hline Físicos & & $\begin{array}{l}\text { Ficar inválido temporariamente, } \\
\text { ficar inválido para sempre, morrer }\end{array}$ \\
\hline Emocionais & & $\begin{array}{l}\text { Ficar nervoso, estressado, } \\
\text { assustado, sofrer, apavorar-se }\end{array}$ \\
\hline Legais & & Ter a motocicleta apreendida, ser multado \\
\hline Financeiros & & $\begin{array}{c}\text { Danos na motocicleta, despesas } \\
\text { com tratamentos, não ter dinheiro } \\
\text { para sustentar-se e sustentar dependentes }\end{array}$ \\
\hline Morais e sociais & & $\begin{array}{l}\text { Ficar inadimplente, não poder } \\
\text { sustentar-se nem sustentar dependentes, } \\
\text { não ter a possibilidade de "crescer" }\end{array}$ \\
\hline
\end{tabular}

vivem a "dialética risco-necessidade": quando só se pode escolher entre trabalhar correndo os riscos do acidente de trânsito ou não trabalhar, o que a maioria das pessoas escolheria?

Considerando que os riscos são inevitáveis, resta aos moto-boys tentar controlá-los.

\section{Tentando o controle dos riscos} do acidente de trânsito

O uso do capacete, obrigatório por lei 7, é considerado pelos moto-boys como o principal equipamento de proteção do motociclista.

Apesar do reconhecimento de que, na eventualidade de um acidente de trânsito, os danos físicos são inevitáveis, os moto-boys não possuem o hábito de usar botas, joelheiras e cotoveleiras, porque, segundo eles, limitam a agilidade exigi- da pela natureza urgente do seu trabalho. Para um moto-boy, quem utiliza os equipamentos de proteção é "fiasquento" (S1G2) e pode receber o apelido de "Robocop" (S1G2).

Os moto-boys também referem habilidades pessoais para o controle do risco do acidente de trânsito.

"Tu tem que te equilibrar no meio do trânsito, cuidar carro, cuidar mau motorista, cuidar tu mesmo se tu é meio louco" (S1G2). "Eu venho me autopoliciando. A profissão exige um autocontrole sem tamanho" (S6G2).

A referência ao autocontrole é, em geral, dirigida ao controle da velocidade, o que, numa profissão caracterizada pela urgência é complicado conseguir, a não ser quando o moto-boy lembra que pode acidentar-se. "Quando tu vês um acidente, tu já sais devagarinho, tu te assustas” (S4G2). 
As informações analisadas sugerem que os moto-boys tomam para si a responsabilidade do autocuidado.

\section{Considerações finais}

As ações de autocuidado podem não ser totalmente eficazes na medida em que a proteção contra os riscos da vida diária não dependem exclusivamente dos indivíduos, mas do contexto desta vida $2,3,4$.

Os promotores da saúde "mandam": "vá devagar, não corra, seja paciente na estrada para não ser no hospital, seja responsável, dirija com a cabeça, tire o pé do acelerador etc". Os moto-boys tentam seguir essas orientações, embora sejam os critérios pessoais e profissionais que prevalecem no cotidiano.

A promoção da saúde dos moto-boys requer ações específicas, multidisciplinares e multisse- toriais que reconheçam a importância do meio na ocorrência de acidentes de trânsito. A regulamentação da profissão, leis que obriguem o uso de proteções para os membros superiores e inferiores, e ações dos promotores da saúde dirigidas também aos patrões e aos clientes dos moto-boys surgem como sugestões desta pesquisa para a prevenção dos acidentes de trânsito envolvendo moto-boys.

O fenômeno do acidente de trânsito envolvendo moto-boys não está relacionado apenas ao comportamento do moto-boy. Ele tem a ver, também, com o meio e com as regras do mercado, estabelecidas por patrões e clientes. O planejamento de ações preventivas precisa considerar, então, todos os agentes e fatores que influem no comportamento arriscado dos moto-boys. Ações mais pontuais, reduzidamente dirigidas à mudança de comportamento dos moto-boys, possivelmente terão pouco sucesso.

\section{Resumo}

Esta nota resulta de uma pesquisa qualitativa realizada na cidade de Porto Alegre, Rio Grande do Sul, Brasil, com o objetivo de explorar o fenômeno "risco do acidente de trânsito" na perspectiva de moto-boys. O estudo foi embasado nas teorias sociológicas sobre risco, em especial, as que enfatizam o caráter sócio-cultural dos seus significados. As informações foram coletadas por meio de grupos focais e analisadas seguindo os passos da Teoria Fundamentada nos Dados. Segundo os moto-boys, os riscos do acidente de trânsito são inerentes ao cotidiano de trabalho e produzidos por interesses pessoais e sociais, no sentido das demandas por dinheiro, velocidade e urgência. Os moto-boys tentam controlar esses riscos utilizando estratégias de autocuidado. Considerando a alta incidência de acidentes de trânsito envolvendo moto-boys em Porto Alegre, parece que tais estratégias têm sido pouco eficazes. A nota argumenta que os acidentes de trânsito envolvendo moto-boys são acidentes de trabalho e, portanto, as ações de promoção da saúde que investem na sua prevenção precisam extrapolar o grupo de indivíduos que pilotam as motocicletas, sendo dirigidas também a clientes e patrões de serviços de telentrega.

Acidentes de Trânsito; Acidentes de Trabalho; Motocicletas; Promoção da Saúde

\section{Colaboradores}

A. M. Veronese redigiu esta nota de pesquisa. D. L. L. C. Oliveira fez a revisão da nota de pesquisa. 


\section{Referências}

1. Veronese AM. Moto-boys de Porto Alegre: convivendo com os riscos do acidente de trânsito [Dissertação de Mestrado]. Porto Alegre: Escola de Enfermagem, Universidade Federal do Rio Grande do Sul; 2004.

2. Petersen A, Lupton D. The new public health: health and self in the age of risk. London: Sage Publications; 1996.

3. Giddens A. Modernidade e identidade. Rio de Janeiro: Jorge Zahar Editor; 2002.

4. Beck U. Risk society: towards a new modernity. London: Sage Publications; 1992.

5. Krueger RA, Casey MA. Focus groups. $3^{\text {rd }}$ Ed. Thousand Oaks: Sage Publications; 2000.

6. Strauss A, Corbin J. Basics of qualitative research: techniques and procedures for developing grounded theory. London: Sage Publications; 1996.

7. Brasil. Lei n. 9.503/97. Institui o Código de Trânsito Brasileiro. Diário Oficial da União 1997; 24 set.

8. Oliveira DLLC. Brazilian adolescent women talk about HIV/AIDS risk: reconceptualizing risky sex. What implications for healt promotion? [PhD Thesis]. London: Institute of Education, University of London; 2001.

9. Ayres JRCM, França Jr. I, Calazans GJ, Saletti Filho HC. O conceito de vulnerabilidade e as práticas de saúde: novas perspectivas e desafios. In: Czeresnia D, Freitas CM, organizadores. Promoção da saúde: conceitos, reflexões, tendências. São Paulo: Editora Hucitec; 2002. p. 117-39.

Recebido em 18/Jan/2005

Versão final reapresentada em 03/Jan/2006

Aprovado em 23/Jun/2006 